\title{
(6) OPEN ACCESS \\ Neonatal outcomes and delivery of care for infants born late preterm or moderately preterm: a prospective population-based study
}

\author{
Elaine M Boyle, ${ }^{1}$ Samantha Johnson, ${ }^{1}$ Bradley Manktelow, ${ }^{1}$ Sarah E Seaton, ${ }^{1}$ \\ Elizabeth S Draper, ${ }^{1}$ Lucy K Smith, ${ }^{1}$ Jon Dorling, ${ }^{2}$ Neil Marlow, ${ }^{3}$ Stavros Petrou, ${ }^{4}$ \\ David J Field ${ }^{1}$
}

\begin{abstract}
${ }^{1}$ Department of Health Sciences, University of Leicester, Leicester, UK ${ }^{2}$ Faculty of Medicine and Health Sciences, University of Nottingham, Nottingham, UK ${ }^{3} U C L$ EGA Institute for Women's Health, London, UK ${ }^{4}$ Warwick Clinical Trials Unit, University of Warwick, Coventry, UK
\end{abstract}

\section{Correspondence to} Dr Elaine M Boyle, Department of Health Sciences, University of Leicester, 22-28 Princess Road West, Leicester LE1 6TP, UK; eb124@le.ac.uk

Received 12 August 2014 Revised 12 December 2014 Accepted 23 December 2014 Published Online First 1 April 2015

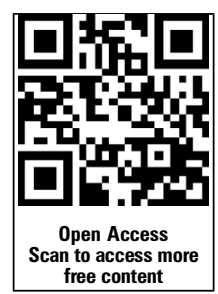

\section{SLinked}

- http://dx.doi.org/10.1136/ fetalneonatal-2014-308136

\section{CrossMark}

To cite: Boyle EM, Johnson S, Manktelow B, et al. Arch Dis Child Fetal Neonatal Ed 2015;100: F479-F485.

\begin{abstract}
Objective To describe neonatal outcomes and explore variation in delivery of care for infants born late (34-36 weeks) and moderately (32-33 weeks) preterm (LMPT). Design/setting Prospective population-based study comprising births in four major maternity centres, one midwifery-led unit and at home between September 2009 and December 2010. Data were obtained from maternal and neonatal records.
\end{abstract}

Participants All LMPT infants were eligible. A random sample of term-born infants ( $\geq 37$ weeks) acted as controls. Outcome measures Neonatal unit (NNU) admission, respiratory and nutritional support, neonatal morbidities, investigations, length of stay and postnatal ward care were measured. Differences between centres were explored.

Results 1146 (83\%) LMPT and 1258 (79\% of eligible) term-born infants were recruited. LMPT infants were significantly more likely to receive resuscitation at birth $(17.5 \%$ vs $7.4 \%)$, respiratory $(11.8 \%$ vs $0.9 \%)$ and nutritional support (3.5\% vs $0.3 \%$ ) and were less likely to be fed breast milk (64.2\% vs $72.2 \%$ ) than term infants. For all interventions and morbidities, a gradient of increasing risk with decreasing gestation was evident. Although $60 \%$ of late preterm infants were never admitted to a NNU, $83 \%$ required medical input on postnatal wards. Clinical management differed significantly between services.

Conclusions LMPT infants place high demands on specialist neonatal services. A substantial amount of previously unreported specialist input is provided in postnatal wards, beyond normal newborn care. Appropriate expertise and planning of early care are essential if such infants are managed away from specialised neonatal settings. Further research is required to clarify optimal and cost-effective postnatal management for LMPT babies.

\section{INTRODUCTION}

Late $\left(34^{+0}-36^{+6}\right.$ weeks $)$ and moderately $\left(32^{+0}-33^{+6}\right.$ weeks) preterm (LMPT) births comprise 6-7\% of UK births and $75 \%$ of all preterm births. ${ }^{1}$ Compared with term-born infants, increased proportions of LMPT infants will require neonatal unit $^{2}$ (NNU) admission for specialist care ${ }^{3-10}$ and develop long-term health and neurodevelopmental problems. ${ }^{11-17}$ Most previous research in this group has been retrospective and/or single centre. A paucity of prospective, population-based research has prevented full evaluation of the impact of LMPT births on delivery of care, resource use or

\section{What is already known on this topic?}

Late and moderately preterm (LMPT) births account for $75 \%$ of all preterm births.

- Infants born between 32 and 36 weeks gestation have an increased risk of neonatal morbidity requiring admission to a neonatal unit (NNU) compared with those born at or beyond 37 weeks gestation, although severe morbidity is uncommon.

\section{What this study adds?}

- LMPT infants generate a significant neonatal healthcare burden relating to large numbers of infants receiving specialist postnatal care and interventions outside NNUs.

- Significant variation between units exists in the delivery of care.

clinical challenges. The extent to which management of these infants reflects local policy or practice as opposed to individual clinical need has not been quantified. In the UK, infants expected to require no medical input are cared for with their mothers by midwives on a normal postnatal ward and are only reviewed by a medical practitioner if there is cause for concern. Within a prospective study, we, therefore, sought to describe neonatal outcomes and delivery of medical care until discharge, both within and outside NNUs, for uncomplicated singleton births and to explore variation in clinical practice with respect to management of these infants.

\section{METHODS}

The Late and Moderately Preterm Birth Study (LAMBS) is a prospective population-based study of outcomes for infants born at 32-36 weeks gestation compared with a random sample of term-born infants. Recruitment was from a selected geographical area (Leicestershire and Nottinghamshire, England) between September 2009 and December 2010. Births occurred in four perinatal centres, one low-risk midwifery-led unit and at home or outside hospital. Each of two major cities within the study area had two maternity units, with neonatal care in 
each city delivered as a single service with staff working across both sites. All live births and stillbirths between $32^{+0}$ and $36^{+6}$ weeks gestation, to women resident in this area at the time of delivery (defined by permanent address postcode), were eligible for inclusion. A control group of term-born infants was selected by random sampling of dates and times of births at $\geq 37^{+0}$ weeks in the same area during the previous year. Families declining involvement were recorded as non-participants. In view of the excess of multiple births that occur at 32-36 weeks gestation, we attempted to recruit all multiples born at $\geq 32$ weeks.

Research midwives sought signed consent from mothers in hospital following delivery or, when early discharge made this impossible, at home. The sample size was based on detecting differences in rates of cognitive impairment using a score of less than -2 SDs below the mean on the Parent Report of Children's Abilities-revised (PARCA-R) to indicate moderatesevere impairment. We estimated that 800 singleton infants per group would provide $80-90 \%$ power to detect clinically important differences in cognitive impairment (term $2 \%$ vs LMPT $5 \%$ ). We chose to oversample, with a target recruitment of 1000 per group. The Derbyshire Multicentre Research ethics committee approved the study.

Research midwives interviewed women using a semistructured questionnaire comprising validated scales and questions. ${ }^{18-20}$ Maternal health, obstetric, sociodemographic and lifestyle data were obtained during interviews and from maternity records. The Index of Multiple Deprivation $2010^{21}$ (IMD 2010) was used to quantify area-level socioeconomic status. Data for NNU and postnatal ward care were abstracted from infants' records, including resuscitation at birth (positive pressure ventilation via mask or endotracheal tube); NNU admission; respiratory support (mechanical ventilation; non-invasive respiratory support, including nasal continuous positive airways pressure and nasal intermittent positive pressure ventilation; oxygen therapy); intravenous fluids; parenteral nutrition; morbidities (hypoglycaemia; jaundice; hypothermia); surgical procedures; investigations (chest X-ray; infection screens; MRI); length of hospital stay; breast milk given during the hospital stay and whether the infant was discharged receiving only breast milk. Medical reviews of infants on postnatal wards were recorded. Recruitment records were cross-checked with maternity unit birth registers. Data were independently double entered into a computer database. Denominator data for all births by gestation within the study area and time period were obtained from maternity centre records. We compared management between neonatal services, including care given outside NNUs, to investigate variation in practice.

\section{STATISTICAL ANALYSIS}

Infants were divided into three groups for analysis: $32^{+0}-33^{+6}$ weeks, $34^{+0}-36^{+6}$ weeks and $\geq 37^{+0}$ weeks. Summary statistics for birth weight, gender and estimated fetal weight ${ }^{22}$ were calculated and presented according to whether the birth was from a singleton or multiple pregnancy. ORs were presented for the odds of having being born LMPT compared with term. Clinical outcomes were summarised for live-born singletons without congenital anomalies; univariable analyses are presented. To test for statistically significant differences between gestational age groups, $\chi^{2}$ tests for trend were used for binary outcomes. Kendall's Tau was used to test for differences in the number of days of interventions. $\chi^{2}$ tests were used to investigate variation in clinical practice.

\section{RESULTS}

\section{Non-participants}

There were 562 non-participants ( 230 LMPT; $332 \geq 37$ weeks). Mothers of 216 (38.4\%) infants could not be contacted following discharge and 346 declined participation. Mothers of stillborn infants were $2.78(95 \%$ CI 1.85 to $4.18 ; \mathrm{p}<0.0001)$ times more likely to be non-participants. Analysis using the IMD $2010^{21}$ showed that non-participation increased linearly with increasing deprivation; those from the most deprived decile were 2.03 (95\% CI 1.54 to 2.68 ) times more likely to be nonparticipants than those from the least deprived.

\section{Study population}

Recruitment and survival to discharge are detailed in figure 1. Of 1376 eligible LMPT births, 1146 (83.3\%) were recruited and of 1590 eligible term births, 1258 (79.1\%) were recruited. Of the 2736 births, $2360(86.2 \%)$ were in hospital; $10(0.4 \%)$ in the midwifery-led unit (all term-born) and 34 at home or outside hospital (including 17 planned home births, 10 term, 3 moderately preterm and 4 late preterm unplanned births). Mothers of $16(44.4 \%)$ LMPT and $3(42.8 \%)$ term stillborn infants agreed to participate.

The characteristics of recruited infants are shown in table 1 . Six live-born singletons died before discharge (four LMPT during the first week; one LMPT and one term-born at $>28$ days). Causes of death were pulmonary haemorrhage in one, pulmonary hypoplasia in two while in three infants, including the term-born infant, death was associated with major congenital anomalies. Small for gestational age births (defined as singletons with birth weight $<3$ rd centile ${ }^{22}$ ) were more common in the LMPT than in the term group $(10.7 \%$ vs $4.3 \%$; $\mathrm{p}<0.001$ ).

\section{Neonatal morbidity in singleton LMPT infants without congenital anomalies}

Outcomes and interventions for uncomplicated LMPT infants are shown in table 2 . There was no statistically significant difference in mortality between LMPT and term groups. LMPT infants were significantly more likely to receive active resuscitation at birth $(17.5 \%$ vs $7.4 \%)$ and to receive respiratory support $(11.8 \%$ vs $0.9 \%)$ or parenteral nutrition $(3.5 \%$ vs $0.3 \%)$ during their neonatal stay. Across groups, for all interventions and morbidities, a significant gradient of increasing risk with decreasing gestation was evident. Receipt of breast milk was less common in LMPT than term-born infants and only $39.3 \%$ of LMPT infants were exclusively breast milk feeding at discharge compared with $65.1 \%$ of term-born infants $(p<0.001)$.

\section{NNU policies}

All policies recommended NNU admission for infants born at $<34$ weeks and/or $<1800 \mathrm{~g}$ birth weight. In one city (Centre 2 ), infants born at 34-36 weeks requiring additional care (nasogastric feeding; $\leq 8$ hourly blood glucose or bilirubin monitoring; active temperature management) could be cared for in a 'transitional care' environment within the postnatal ward (ie, the mother provided normal care for the baby, with support from a healthcare professional), which prompted a daily review by NNU medical staff. In the other city, where no such policy existed, such infants were admitted to neonatal care for nasogastric feeding, but otherwise remained on a postnatal ward. 


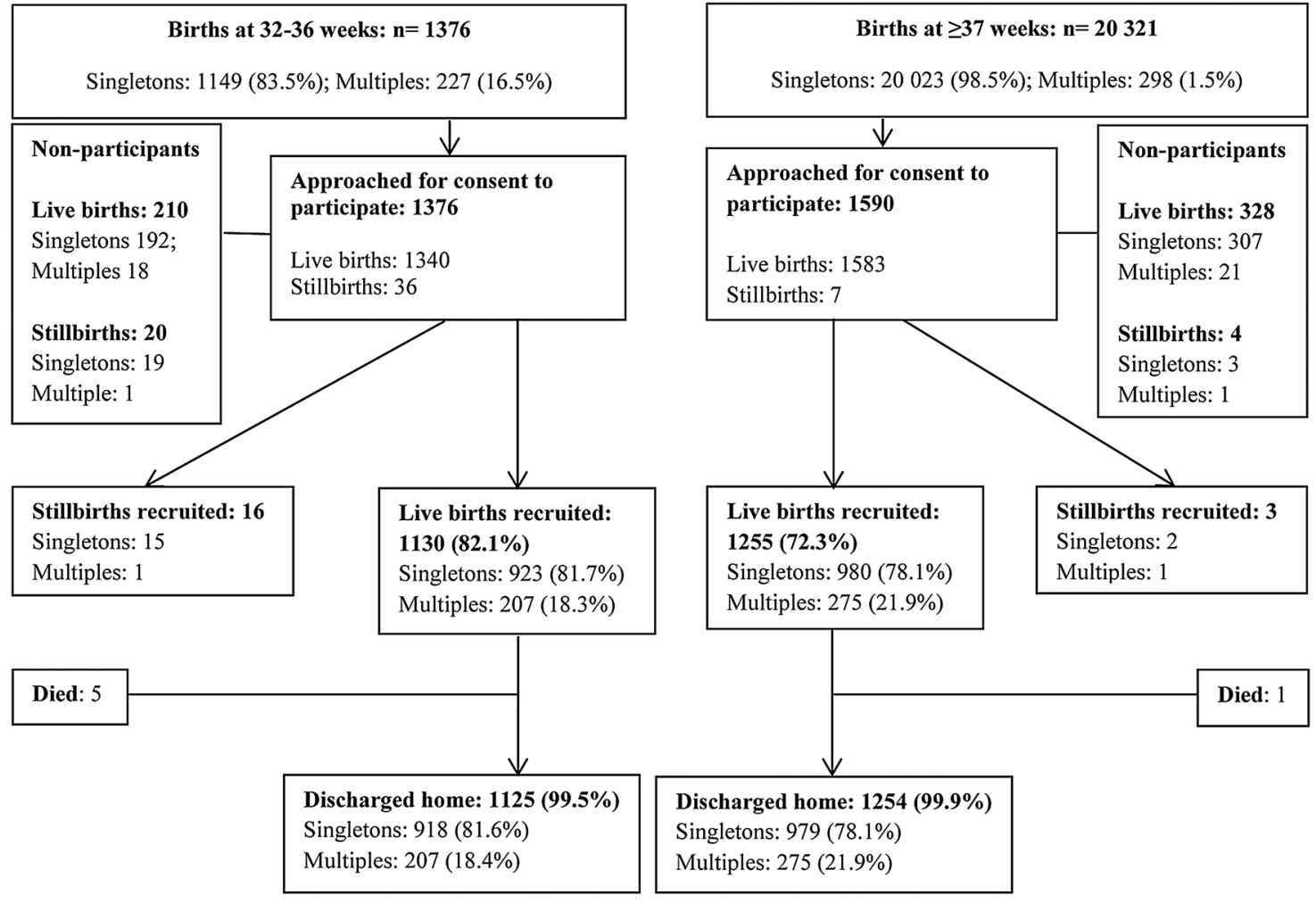

Figure 1 Flowchart to show recruitment to the Late and Moderately Preterm Birth Study (LAMBS).

\section{Delivery of neonatal care}

Of 34 home births, all three moderately preterm infants and one late preterm infant were admitted to a NNU. Three late preterm infants born outside hospital were admitted to a postnatal ward. Of 27 home births at term, eight (29.6\%) were admitted to hospital, one (3.7\%) to a NNU and seven (25.9\%) to a postnatal ward. All infants born in the low-risk midwifery-led centre received the entirety of their neonatal care there.

All moderately preterm infants and $35.7 \%$ of late preterm singletons received all or part of their care on a NNU compared with $4.4 \%$ of term-born infants. Moderately preterm infants were admitted immediately after birth and only 11 (9\%) spent any time (median (range) 4 (2-7) days) on a postnatal ward prior to discharge.

In contrast, late preterm singletons received a total of 2834 days of care on postnatal wards, contributing $58.9 \%$ of the total hospital stay for this group. Five hundred and five (64.3\%) late preterm infants received all neonatal care on a postnatal ward. However, although never admitted to a NNU, $422(83.6 \%)$ of these infants received at least one review by a medical practitioner in addition to the routine newborn examination. Some were planned reviews, carried out according to local policy for prematurity or because of issues identified antenatally, but the majority $(59.5 \% ; n=251)$ were unanticipated, requested because of concerns about the infant's condition. In contrast, only $24 \%$ of term infants receiving entirely postnatal ward care received extra medical reviews. Table 3 shows the types of interventions given to late preterm and term singletons receiving postnatal care in hospital, but outside a NNU. Active management or monitoring of glycaemic control, jaundice and temperature were all significantly more common in late preterm infants than in term-born infants $(\mathrm{p}<0.001)$. In two units, some care within the postnatal ward was designated as 'transitional care'. This comprised sole care for $48.4 \%$ of late preterm infants and a portion of care for a further $18.3 \%$; in the other units, $62.4 \%$ received normal postnatal ward care.

The regions incorporating the centres included in the study had a similar population mix and the neonatal centres were of comparable size. There were no significant differences between neonatal services with respect to birth gestation and gender of recruited infants. However, comparisons between neonatal services highlighted differences, mainly relating to NNU management of LMPT infants, including approaches to respiratory support, fluids and nutrition. Infants in the centre where infants received more of these types of support had a significantly longer hospital stay (table 4).

\section{DISCUSSION}

This birth cohort provides the first prospective population-based data estimating the increased neonatal healthcare treatments associated with LMPT births in the UK. For infants born at 3236 weeks gestation, NNU admission, neonatal morbidities, therapeutic interventions, investigations and regular monitoring by medical staff were all more common than for those born at $\geq 37$ weeks.

Analyses across gestational age groups demonstrated increasing risk of morbidity with decreasing gestation. Death among LMPT infants without congenital anomalies was rare and approximately two-thirds received postnatal ward care only. It therefore seems reasonable to conclude that uncomplicated singleton LMPT births are not associated with high risk of severe or complex adverse neonatal outcomes. Our results nevertheless highlight an effect of LMPT births on overall demand for neonatal specialist care, evidenced by increased numbers of LMPT infants receiving resuscitation at birth, respiratory support, parenteral nutrition and 
Table 1 The characteristics of all births recruited to LAMBS

\begin{tabular}{|c|c|c|c|c|c|}
\hline & \multicolumn{2}{|c|}{ Late and moderately preterm (LMPT) } & \multirow{2}{*}{$\begin{array}{l}\text { Term } \\
\geq 37 \text { weeks }\end{array}$} & \multirow[b]{2}{*}{$\mathrm{OR}^{*}$} & \multirow[b]{2}{*}{ p Value } \\
\hline & 32-33 weeks & 34-36 weeks & & & \\
\hline \multicolumn{6}{|l|}{ Singleton births } \\
\hline $\mathrm{N}$ (all births) & 132 & 806 & 982 & & \\
\hline N (live births) & 124 & 799 & 980 & & \\
\hline \multicolumn{6}{|l|}{ Male sex } \\
\hline All births, n (\%) & $76(57.6)$ & $447(55.5)$ & $503(51.2)$ & $1.20(1.00,1.44)$ & 0.05 \\
\hline Live births, n (\%) & $69(55.7)$ & $443(55.4)$ & $503(51.3)$ & $1.18(0.99,1.41)$ & 0.07 \\
\hline \multicolumn{6}{|l|}{ Congenital anomalies } \\
\hline All births, n (\%) & $2(1.5)$ & $14(1.7)$ & $8(0.8)$ & $2.11(0.90,4.96)$ & 0.09 \\
\hline Live births, n (\%) & $2(1.6)$ & $14(1.8)$ & $8(0.8)$ & $2.14(0.91,5.03)$ & 0.08 \\
\hline \multicolumn{6}{|c|}{ Birth weight $<3$ rd fetal centile } \\
\hline All births, n (\%) & $21(15.9)$ & $83(10.3)$ & $42(4.3)$ & $2.79(1.93,4.04)$ & $<0.001$ \\
\hline Live births, $\mathrm{n}(\%)$ & $18(14.5)$ & $81(10.1)$ & $42(4.3)$ & $2.68(1.84,3.90)$ & $<0.001$ \\
\hline \multicolumn{6}{|c|}{ Birth weight $<10$ th fetal centile } \\
\hline All births, n (\%) & $32(24.2)$ & $161(20.0)$ & $114(11.6)$ & $1.97(1.53,2.54)$ & $<0.001$ \\
\hline Live births, n (\%) & $28(22.6)$ & $159(19.9)$ & $114(11.6)$ & $1.93(1.50,2.49)$ & $<0.001$ \\
\hline \multicolumn{6}{|c|}{ Birth weight $>90$ th fetal centile } \\
\hline All births, n (\%) & $20(15.2)$ & $107(13.3)$ & $109(11.1)$ & $1.25(0.95,1.65)$ & 0.10 \\
\hline Live births, n (\%) & $20(16.1)$ & $106(13.3)$ & $108(13.3)$ & $1.28(0.97,1.68)$ & 0.08 \\
\hline \multicolumn{6}{|c|}{ Birth weight $>97$ th fetal centile } \\
\hline All births, n (\%) & $12(9.1)$ & $54(6.7)$ & $39(4.0)$ & $1.83(1.22,2.75)$ & 0.004 \\
\hline Live births, n (\%) & $12(9.7)$ & $53(6.6)$ & $39(4.0)$ & $1.83(1.22,2.75)$ & 0.004 \\
\hline \multicolumn{6}{|l|}{ Multiple births } \\
\hline N (all births) & 30 & 178 & 276 & & \\
\hline N (live births) & 30 & 177 & 275 & & \\
\hline \multicolumn{6}{|l|}{ Male sex } \\
\hline All births, n (\%) & $12(40.0)$ & $86(48.3)$ & $148(53.6)$ & $0.77(0.54,1.11)$ & 0.16 \\
\hline Live births, n (\%) & $12(40.0)$ & $85(48.0)$ & $148(53.8)$ & $0.76(0.53,1.08)$ & 0.13 \\
\hline \multicolumn{6}{|l|}{ Congenital anomalies } \\
\hline All births, n (\%) & $5(16.7)$ & $2(1.1)$ & $1(0.4)$ & $9.58(1.17,78.46)$ & 0.04 \\
\hline Live births, n (\%) & $5(16.7)$ & $2(1.1)$ & $1(0.4)$ & $9.59(1.17,78.56)$ & 0.04 \\
\hline \multicolumn{6}{|c|}{ Birth weight $<3$ rd fetal centile } \\
\hline All births, n (\%) & $4(13.3)$ & $33(18.5)$ & $53(19.2)$ & $0.91(0.57,1.45)$ & 0.69 \\
\hline Live births, n (\%) & $4(13.3)$ & 33 (18.6) & $52(18.9)$ & $0.93(0.59,1.49)$ & 0.77 \\
\hline \multicolumn{6}{|c|}{ Birth weight $<10$ th fetal centile } \\
\hline All births, n (\%) & $8(26.7)$ & $65(36.5)$ & $118(42.8)$ & $0.72(0.50,1.05)$ & 0.09 \\
\hline Live births, n (\%) & $8(26.7)$ & $65(36.7)$ & $117(42.6)$ & $0.74(0.51,1.07)$ & 0.11 \\
\hline \multicolumn{6}{|c|}{ Birth weight $>90$ th fetal centile } \\
\hline All births, n (\%) & $0(0.0)$ & $5(2.8)$ & $6(2.2)$ & $1.11(0.33,3.69)$ & 0.87 \\
\hline Live births, n (\%) & $0(0.0)$ & $5(2.8)$ & $6(2.2)$ & $1.11(0.33,3.69)$ & 0.87 \\
\hline \multicolumn{6}{|c|}{ Birth weight $>97$ th fetal centile } \\
\hline All births, n (\%) & $0(0.0)$ & $1(0.6)$ & $2(0.7)$ & $0.66(0.06,7.35)$ & 0.74 \\
\hline Live births, n (\%) & $0(0.0)$ & $1(0.6)$ & $2(0.7)$ & $0.66(0.06,7.36)$ & 0.74 \\
\hline
\end{tabular}

treatment for common morbidities. Large numbers of these infants mean that a substantial amount of specialist expertise is devoted to this group.

There was a noticeable effect of LMPT births on length of hospital stay, related to medical care for late preterm infants on postnatal wards. We have demonstrated that even late preterm infants deemed 'healthy' enough not to require NNU admission do not follow the same clinical course as term-born infants, receiving substantial additional care, monitoring and intervention and being less likely to be fed breast milk. We have also highlighted differences in clinical management between neonatal services, both in the NNU and outside.

\section{Strengths and limitations}

Major strengths of this study are the population-based design and inclusion of randomly selected term-born controls. We have also explored the care needed by these infants in different postnatal settings. Neonatal research and routine data collection have previously focused on very preterm or high-risk births and/ or specialist NNU care. Access to detailed data for infants not admitted to a NNU is therefore unusual. Data available for LAMBS infants enable us to capture additional use of resources that other reports have been unable to highlight.

Our results are consistent with other reports highlighting the need for neonatal intervention in a significant proportion of 
Table 2 Clinical outcomes for live-born singletons without congenital anomalies

\begin{tabular}{|c|c|c|c|c|}
\hline & \multicolumn{2}{|l|}{ LMPT } & \multirow{2}{*}{$\begin{array}{l}\text { Term } \\
\geq 37 \text { weeks }\end{array}$} & \multirow[b]{2}{*}{ p Value* } \\
\hline & $32^{+0}-33^{+6}$ weeks & $34^{+0}-36^{+6}$ weeks & & \\
\hline Number of infants, $n$ & 122 & 785 & 972 & \\
\hline \multicolumn{5}{|l|}{ Place of birth } \\
\hline Hospital, n (\%) & $119(97.5)$ & $780(99.4)$ & $938(96.5)$ & \\
\hline Midwifery-led unit, n (\%) & $0(0.0)$ & $1(0.1)$ & $9(0.9)$ & \\
\hline Home/outside hospital & $3(0.0)$ & $4(0.5)$ & $25(2.6)$ & \\
\hline Deaths before discharge, $\mathrm{n}(\%)$ & $2(1.6)$ & $1(0.1)$ & $1(0.1)$ & \\
\hline Any active resuscitation at birth, $\mathrm{n}(\%)$ & $45(36.9)$ & $114(14.5)$ & $72(7.4)$ & $<0.001$ \\
\hline Endotracheal intubation at birth, $\mathrm{n}(\%)$ & $11(9.0)$ & $19(2.4)$ & $8(0.8)$ & $<0.001$ \\
\hline \multicolumn{5}{|l|}{ Delivery of postnatal care } \\
\hline All newborn care on postnatal ward (overall), n (\%) & $0(0.0)$ & $505(64.3)$ & $910(93.6)$ & $<0.001$ \\
\hline Any care in a NNU (overall), $\mathrm{n}(\%)$ & $122(100.0)$ & $280(35.7)$ & $43(4.4) \dagger$ & $<0.001$ \\
\hline All care on postnatal ward, $n(\%)$ of those born in hospital & $0(0.0)$ & $501(64.2)$ & $896(95.5)$ & \\
\hline Any care in a NNU, $n(\%)$ of those born in hospital & $118(100.0)$ & $279(35.8)$ & $42(4.5)$ & \\
\hline All care on a postnatal ward, $n(\%)$ of those born in midwifery-led unit & $0(0.0)$ & $1(100.0)$ & $9(100.0)$ & \\
\hline Any care in a NNU, $\mathrm{n}(\%)$ of those born in midwifery-led unit & $0(0.0)$ & $0(0.0)$ & $0(0.0)$ & \\
\hline All care on a postnatal ward, $\mathrm{n}(\%)$ of those born at home & $0(0.0)$ & $3(75.0)$ & $5(20.0)$ & \\
\hline Any care in a NNU, $n(\%)$ of those born at home $\ddagger$ & $3(100.0)$ & $1(25.0)$ & $1(4.0)$ & \\
\hline Length of hospital stay, days, median (range) & $16(4,78)$ & $4(1,49)$ & $2(0,25)$ & $0.013 \S$ \\
\hline Surgical procedures, n (\%) & $2(1.7)$ & $3(0.4)$ & $0(0.0)$ & 0.002 \\
\hline \multicolumn{5}{|l|}{ Maximum level of respiratory support } \\
\hline Mechanical ventilation, $\mathrm{n}(\%)$ & $27(22.1)$ & $48(6.1)$ & $8(0.8)$ & \\
\hline Non-invasive respiratory support, $\mathrm{n}(\%)$ & $14(11.5)$ & $18(2.3)$ & $1(0.1)$ & \\
\hline Oxygen therapy, n (\%) & $6(4.9)$ & $30(3.8)$ & $8(0.8)$ & \\
\hline No respiratory support, $n$ (\%) & $75(61.5)$ & $689(87.8)$ & $955(98.3)$ & $<0.001$ \\
\hline \multicolumn{5}{|l|}{ Ventilation and/or non-invasive respiratory support } \\
\hline $\mathrm{n}(\%)$ & $41(33.6)$ & $66(8.4)$ & $9(0.9)$ & $<0.001$ \\
\hline $\begin{array}{l}\text { Days of mechanical ventilation and non-invasive } \\
\text { respiratory support, median (range) }\end{array}$ & $2(1,26)$ & $2(1,13)$ & $3(1,4)$ & $0.078 \S$ \\
\hline \multicolumn{5}{|l|}{ Parenteral nutrition } \\
\hline $\mathrm{n}(\%)$ & $15(12.3)$ & $17(2.2)$ & $3(0.3)$ & $<0.001$ \\
\hline Days of parenteral nutrition, median (range) & $8(2,60)$ & $4(1,32)$ & $3(3,3)$ & $0.10 \S$ \\
\hline \multicolumn{5}{|l|}{ Intravenous (IV) fluids } \\
\hline $\mathrm{n}(\%)$ & $84(68.9)$ & $159(20.3)$ & $20(2.1)$ & $<0.001$ \\
\hline Days of IV fluids, median (range) & $2(1,11)$ & $2(1,14)$ & $2.5(1,10)$ & $0.053 \S$ \\
\hline \multicolumn{5}{|l|}{ Days to full oral suck feeds } \\
\hline Median (range) & $12(0,32)$ & $0(0,95)$ & $0(0,19)$ & $0.016 \S$ \\
\hline Nasogastric feeds on discharge, $\mathrm{n}(\%)$ & $2(1.7)$ & $1(0.1)$ & $0(0.0)$ & 0.002 \\
\hline Any breast milk given, $\mathrm{n}(\%)$ & $81(66.4)$ & $501(63.8)$ & $717(73.8)$ & $<0.001$ \\
\hline Receiving breast milk at discharge, $\mathrm{n}(\%)$ & $64 / 120(53.3)$ & $460 / 784(58.7)$ & $701 / 971(72.2)$ & $<0.001$ \\
\hline Exclusive breast milk feeding at discharge, $\mathrm{n}(\%)$ & $41 / 120(34.2)$ & $314 / 784(40.0)$ & $632 / 971(65.1)$ & $<0.001$ \\
\hline Jaundice treated with phototherapy, n (\%) & $72(59.0)$ & $127(16.2)$ & $6(0.6)$ & $<0.001$ \\
\hline Hypothermia (temperature $<36.0^{\circ} \mathrm{C}$ ), n (\%) & $11(9.0)$ & $73(9.3)$ & $12(1.2)$ & $<0.001$ \\
\hline Hypoglycaemia (blood glucose $<2.0 \mathrm{mmol} / \mathrm{L}$ ), n (\%) & $16(13.1)$ & $45(5.7)$ & $9(0.9)$ & $<0.001$ \\
\hline \multicolumn{5}{|l|}{ Investigations } \\
\hline Cranial ultrasound scan, n (\%) & $28(23.0)$ & $35(4.5)$ & $14(1.4)$ & $<0.001$ \\
\hline MRI scan, n (\%) & $1(0.8)$ & $7(0.9)$ & $5(0.5)$ & 0.39 \\
\hline Chest X-ray, n (\%) & $53(43.4)$ & $122(15.5)$ & $23(2.4)$ & $<0.001$ \\
\hline Screen for suspected sepsis, n (\%) & $76(62.3)$ & $251(32.0)$ & $48(4.9)$ & $<0.001$ \\
\hline Positive culture results, n (\%) & $3(2.5)$ & $13(1.7)$ & $0(0.0)$ & $<0.001$ \\
\hline
\end{tabular}

LMPT infants. 581023 However, variation in clinical practice between centres has rarely been studied in more mature preterm infants. $^{24} 25$ Delivery of care and outcomes for low-risk infants in a postnatal ward rather than a NNU environment have not previously been explored. The additional neonatal care that we have highlighted, delivered to these infants in postnatal wards, would not have been detected by previous studies that have not measured these clinical and resource requirements. 
Table 3 Medical care and interventions delivered to singleton infants who were never admitted to a NNU

\begin{tabular}{|c|c|c|c|}
\hline & $\begin{array}{l}34-36 \\
\text { weeks }\end{array}$ & $\begin{array}{l}\geq 37 \\
\text { weeks }\end{array}$ & p Value* \\
\hline $\begin{array}{l}\text { Infants receiving all care outside a NNU, } \\
\mathrm{n}(\%)\end{array}$ & $505(64.3)$ & 910 (93.6) & $<0.001$ \\
\hline $\begin{array}{l}\text { Length of hospital stay, median (range), } \\
\text { days }\end{array}$ & $4(1,16)$ & $2(1,14)$ & $0.019 \dagger$ \\
\hline Reviewed by medical practitioner, $\mathrm{n}(\%)$ & $422(83.6)$ & $218(24.0)$ & $<0.001$ \\
\hline More than one medical review, n (\%) & $332(78.7)$ & $106(48.6)$ & $<0.001$ \\
\hline \multicolumn{4}{|l|}{ Reason for medical review, n (\%) } \\
\hline $\begin{array}{l}\text { Planned postnatal review for } \\
\text { antenatal concern }\end{array}$ & 48 (11.6) & $66(30.3)$ & \\
\hline Postnatal clinical concern & $251(59.5)$ & $152(69.7)$ & \\
\hline $\begin{array}{l}\text { Routine review for prematurity/low } \\
\text { birth weight }\end{array}$ & $121(28.5)$ & $0(0.0)$ & $<0.001$ \\
\hline \multicolumn{4}{|l|}{ Interventions } \\
\hline Active temperature management, $\mathrm{n}(\%)$ & $52(10.3)$ & $8(0.9)$ & $<0.001$ \\
\hline $\begin{array}{l}\text { Regular blood glucose or bilirubin } \\
\text { monitoring, } \mathrm{n}(\%)\end{array}$ & $116(23.0)$ & $22(2.4)$ & $<0.001$ \\
\hline Phototherapy, n (\%) & $31(6.1)$ & $3(0.3)$ & $<0.001$ \\
\hline$\geq 4$ hourly nursing observations, $n(\%)$ & $311(61.6)$ & 125 (13.7) & $<0.001$ \\
\hline
\end{tabular}

Limitations are primarily related to inability to recruit the whole population of LMPT births, because parents could not be contacted or declined participation. Non-participants were more likely to be of lower socioeconomic status than those who gave consent, which may have introduced sampling bias. However, acknowledged associations between socioeconomic deprivation and poor health ${ }^{26} 27$ suggest that this would be likely to result in underestimation of adverse outcomes.

\section{Implications for delivery of neonatal care}

LMPT infants have been viewed as having high survival rates and good outcomes. ${ }^{4}$ In most neonatal centres, moderately preterm infants receive NNU care from birth. For normally formed late preterm infants, desire to avoid separating infants and mothers and the perception that they are unlikely to require significantly different newborn care from term-born infants have meant that many receive care on postnatal wards.

Supplementary postnatal support outside a NNU may include phototherapy, nasogastric feeding, intravenous antibiotic administration, temperature management and other regular monitoring. How and where this support is given depends on local configuration of services and policy. Delivery of 'transitional care', where the mother provides normal care for the baby, with support from professionals, is ill-defined and inconsistent across the UK, with blurring of the boundaries between specialist and normal newborn care. Provision, classification, reporting and costs of such care over and above routine normal newborn care vary between services. Currently, medical input for infants on postnatal wards is often provided by medical staff from the specialist NNU team. Whether or not such care could be safely, appropriately and more cost-effectively delivered by other appropriately trained individuals has not been explored.

There have been calls for more intensive early monitoring for all late preterm infants. ${ }^{6}$ It is not known whether such increased vigilance prevents or leads to earlier detection of neonatal problems or reduces length of stay. Potential risks must be balanced against benefits of keeping mother and baby together. However, in our study, for approximately $50 \%$ of inborn late preterm infants admitted to a NNU, the decision to admit was taken more than $2 \mathrm{~h}$ after birth, suggesting that there may have been unrealistic expectations that infants would not require specialist management. The impact of delaying initiation of specialist NNU care in this way is unknown.

Differences between neonatal services suggest that some of the resource use attributable to LMPT infants is related to local differences in approaches to clinical management. There remains a paucity of evidence relating to LMPT infants about even basic aspects of care such as enteral and parenteral feeding and the appropriateness of procedures such as routine cranial ultrasound. This appears to have led to important differences in how these infants are managed and consequently in the cost of providing care. These different approaches seem unlikely to be evidence based, yet the financial implications within the National Health Service may be significant. The impact of such differences in neonatal care on important long-term outcomes in this group is not known and requires further investigation.

\section{CONCLUSIONS}

In contrast to very preterm infants, serious neonatal morbidity in LMPT infants is uncommon. However, even modest increases in morbidity in this sizeable group exert very significant demands on neonatal services. A substantial amount of specialist input is provided on postnatal wards, over that which can be classed as 'normal newborn care'. Much of this additional burden has been previously unrecognised. Variation in the provision of 'transitional care', care offered in this setting and associated outcomes warrant further exploration. Nevertheless, it is clear that appropriate staff expertise and resources should be available if infants receive their postnatal care in an environment

Table 4 Clinical management of singleton infants without congenital anomalies born $32^{+0}-36^{+6}$ weeks $(n=907)$ by neonatal service

\begin{tabular}{|c|c|c|c|c|c|c|c|c|c|}
\hline & \multicolumn{3}{|c|}{ Maximum respiratory support given } & \multirow[b]{2}{*}{$\begin{array}{l}\text { Parenteral } \\
\text { nutrition, } \\
\mathrm{n}(\%)\end{array}$} & \multirow[b]{2}{*}{$\begin{array}{l}\text { Intravenous } \\
\text { fluids, } \mathbf{n}(\%)\end{array}$} & \multirow[b]{2}{*}{$\begin{array}{l}\text { Phototherapy, } \\
\text { n (\%) }\end{array}$} & \multirow[b]{2}{*}{$\begin{array}{l}\text { Cranial } \\
\text { ultrasound, } \\
\mathrm{n}(\%)\end{array}$} & \multirow{2}{*}{$\begin{array}{l}\text { Days to } \\
\text { full feeds, } \\
\text { median } \\
\text { (range) }\end{array}$} & \multirow[b]{2}{*}{$\begin{array}{l}\text { LOS, } \\
\text { median } \\
\text { (range) }\end{array}$} \\
\hline & $\begin{array}{l}\text { Mechanical } \\
\text { ventilation, } \\
\mathrm{n}(\%)\end{array}$ & $\begin{array}{l}\text { Non-invasive } \\
\text { respiratory } \\
\text { support, } n(\%)\end{array}$ & $\begin{array}{l}\text { Oxygen } \\
\text { therapy, } \\
n(\%)\end{array}$ & & & & & & \\
\hline Centre $1(n=543)$ & $37(6.8)$ & $29(5.3)$ & $16(3.0)$ & $4(0.7)$ & $131(24.1)$ & $137(25.2)$ & $23(4.2)$ & $0(0,93)$ * & $4(1,36)$ \\
\hline Centre $2(n=364)$ & $38(10.4)$ & $3(0.8)$ & $20(5.5)$ & $28(7.7)$ & $112(30.8)$ & $62(17.0)$ & $40(11.0)$ & $0(0,95)^{*}$ & $6.5(1,78)$ \\
\hline $\mathrm{p}$ Value & 0.05 & $<0.001$ & 0.05 & $<0.001$ & 0.03 & 0.003 & $<0.001$ & $0.03 t$ & $0.03 t$ \\
\hline
\end{tabular}


other than that of a specialist NNU. Further research is required to clarify how, and in what setting, LMPT infants are best managed and who could most efficiently and cost-effectively deliver their care.

Acknowledgements We would like to thank families who participated in LAMBS. This article presents independent research funded by the National Institute for Health Research (NIHR) under its Programme Grants for Applied Research (PGfAR) Programme (Grant Reference Number RP-PG-0407-10029). The views expressed are those of the author(s) and not necessarily those of the NHS, the NIHR or the Department of Health. Neil Marlow receives a proportion of funding from the Department of Health's NIHR Biomedical Research Centres funding scheme at UCLH/UCL.

Contributors EMB conceptualised and designed the study, supervised data collection and study progress, drafted and revised the manuscript and approved the final manuscript for submission. SJ supervised data collection and study progress, critically reviewed and revised the manuscript and approved the final manuscript for submission. BM conceptualised and designed the study, supervised data analyses, critically reviewed and revised the manuscript and approved the final manuscript for submission. SES performed data analyses, critically reviewed and revised the manuscript and approved the final manuscript for submission. ESD conceptualised and designed the study, critically reviewed and revised the manuscript and approved the final manuscript for submission. LKS conceptualised and designed the study, performed data analyses, critically reviewed and revised the manuscript and approved the final manuscript for submission. JD supervised data collection, critically reviewed and revised the manuscript and approved the final manuscript for submission. NM conceptualised and designed the study, critically reviewed and revised the manuscript and approved the final manuscript for submission. SP conceptualised and designed the study, critically reviewed and revised the manuscript and approved the final manuscript for submission. DJF conceptualised and designed the study, critically reviewed and revised the manuscript and approved the final manuscript for submission.

Funding National Institute for Health Research Programme Grants for Applied Research.

Competing interests None.

Ethics approval Derbyshire Multicentre Research ethics committee.

Provenance and peer review Not commissioned; externally peer reviewed.

Data sharing statement On completion of all planned data analyses, requests from external parties to the authors for additional data will be considered. Any data sharing will involve anonymised data only.

Open Access This is an Open Access article distributed in accordance with the Creative Commons Attribution Non Commercial (CC BY-NC 4.0) license, which permits others to distribute, remix, adapt, build upon this work non-commercially, and license their derivative works on different terms, provided the original work is properly cited and the use is non-commercial. See: http://creativecommons.org/ licenses/by-nc/4.0/

\section{REFERENCES}

1 Moser K, Macfarlane A, Chow YH, et al. Introducing new data on gestation-specific infant mortality among babies born in 2005 in England and Wales. Health Stat Q 2007;(35):13-27.

2 BAPM. British Association of Perinatal Medicine categories of care. London, UK, 2011.

3 Dani C, Corsini I, Piergentili L, et al. Neonatal morbidity in late preterm and term infants in the nursery of a tertiary hospital. Acta Paediatr 2009;98:1841-3.
4 Escobar GJ, Clark RH, Greene JD. Short-term outcomes of infants born at 35 and 36 weeks gestation: we need to ask more questions. Semin Perinatol 2006;30:28-33.

5 Gouyon JB, Vintejoux A, Sagot $P$, et al. Neonatal outcome associated with singleton birth at 34-41 weeks of gestation. Int J Epidemiol 2010;39:769-76.

6 Ishiguro A, Namai Y, Ito YM. Managing "healthy" late preterm infants. Pediatr Int 2009;51:720-5

7 Kalyoncu O, Aygun C, Cetinoglu E, et al. Neonatal morbidity and mortality of late-preterm babies. J Matern Fetal Neonatal Med 2010;23:607-12.

8 Kitsommart R, Janes M, Mahajan V, et al. Outcomes of late-preterm infants: a retrospective, single-center, Canadian study. Clin Pediatr (Phila) 2009;48: 844-50.

9 Leone $A$, Ersfeld $\mathrm{P}$, Adams $\mathrm{M}$, et al. Neonatal morbidity in singleton late preterm infants compared with full-term infants. Acta Paediatr 2012;101:e6-10.

10 Wang ML, Dorer DJ, Fleming MP, et al. Clinical outcomes of near-term infants. Pediatrics 2004; 114:372-6.

11 Baron IS, Erickson K, Ahronovich MD, et al. Cognitive deficit in preschoolers born late-preterm. Early Hum Dev 2011;87:115-19.

12 Boyle EM, Poulsen G, Field DJ, et al. Effects of gestational age at birth on health outcomes at 3 and 5 years of age: population based cohort study. BMJ 2012;344: e896.

13 Chyi LJ, Lee HC, Hintz SR, et al. School outcomes of late preterm infants: special needs and challenges for infants born at 32 to 36 weeks gestation. J Pediatr 2008:153:25-31.

14 Morse SB, Zheng $H$, Tang $Y$, et al. Early school-age outcomes of late preterm infants. Pediatrics 2009;123:e622-9.

15 Romeo DM, Di Stefano A, Conversano M, et al. Neurodevelopmental outcome at 12 and 18 months in late preterm infants. Eur J Paediatr Neurol 2010;14:503-7.

16 Talge NM, Holzman C, Wang J, et al. Late-preterm birth and its association with cognitive and socioemotional outcomes at 6 years of age. Pediatrics 2010;126:1124-31.

17 Woythaler MA, McCormick MC, Smith VC. Late preterm infants have worse 24-month neurodevelopmental outcomes than term infants. Pediatrics 2010;127: e622-9.

18 Brugha T, Bebbington $\mathrm{P}$, Tennant $\mathrm{C}$, et al. The list of threatening experiences: a subset of 12 life event categories with considerable long-term contextual threat. Psychol Med 1985;15:189-94.

19 Brugha TS, Cragg D. The list of threatening experiences: the reliability and validity of a brief life events questionnaire. Acta Psychiatr Scand 1990;82: $77-81$.

20 Office of National Statistics. The Classification of Ethnic Groups: ONS; 2001 [cited 2013, March 24 2014]. http://web.archive.org/web/20070406195623/http://www. statistics.gov.uk/about/Classifications/ns_ethnic_classification.asp

21 McLennan D, Barnes H, Noble M, et al. The English indices of deprivation 2010. London: Department for Communities and Local Government, 2011.

22 Gardosi J, Francis A. GROW Customised Centile Calculators v5.16 [13 December 2013]. http://www.gestation.net/birthweight_centiles/birthweight_centiles.htm

23 Khashu M, Narayanan M, Bhargava S, et al. Perinatal outcomes associated with preterm birth at 33 to 36 weeks' gestation: a population-based cohort study. Pediatrics 2009:123:109-13.

24 Aliaga S, Boggess K, Ivester TS, et al. Influence of neonatal practice variation on outcomes of late preterm birth. Am J Perinatol 2014;31:659-66.

25 Aliaga S, Price W, McCaffrey M, et al. Practice variation in late-preterm deliveries: a physician survey. J Perinatol 2013;33:347-51.

26 Marmot M. Fair society, healthy lives: the Marmot review: strategic review of health inequalities in England post-2010. London: UCL Institute of Health Equity, 2010.

27 Marmot M, Goldblatt P. Importance of monitoring health inequalities. Bmj 2013;347:f6576. 